Article

\title{
Transforming Municipal Solid Waste into Construction Materials
}

\author{
Massoud Sofi ${ }^{1, *(\mathbb{D})}$, Ylias Sabri ${ }^{2, * \mathbb{C}}$, Zhiyuan Zhou $^{1}$ and Priyan Mendis ${ }^{1}$ \\ 1 Department of Infrastructure Engineering, The University of Melbourne, Parkville, Victoria 3010, Australia; \\ zhiyuan.zhou@unimelb.edu.au (Z.Z.); pamendis@unimelb.edu.au (P.M.) \\ 2 Centre for Advanced Materials and Industrial Chemistry, School of Science, College of Science, \\ Engineering \& Health, RMIT University, Melbourne, Victoria 3001, Australia \\ * Correspondence: massoud@unimelb.edu.au (M.S.); ylias.sabri@rmit.edu.au (Y.S.)
}

Received: 27 February 2019; Accepted: 23 April 2019; Published: 9 May 2019

check for updates

\begin{abstract}
Rapid urbanisation and the associated infrastructure development are creating a deficit of conventional construction materials and straining the natural resources. On the other hand, municipal solid waste (MSW) disposal poses a serious environmental problem. Landfilling of MSW is both costly and polluting. Incineration of MSW to generate energy is a commonly adopted approach. However, there are concerns associated with micro pollutants emitted from the combustion process. The carbon footprint of the process and the environmental cost-benefit balancing are disputable. There is clearly a need to adopt cost-effective alternatives to treat MSW. This paper proposes the potential application of "treated" MSW as an ingredient for construction materials. The treatment process involves placing MSW in an autoclave at $150{ }^{\circ} \mathrm{C}$ with 5 bars $(0.5 \mathrm{MPa})$, followed by the separation of metals, plastics and glass for recycling purposes. The end-product, which is a semi-organic mixture (referred to as 'biomass'), is passed through a vortex-oscillation system, which makes it more uniform as a material. Compressive testing of Portland cement-based pastes containing $10 \%$ and $15 \%$ biomass shows consistency in the results, demonstrating the potential use of biomass in construction materials.
\end{abstract}

Keywords: biomass; municipal solid waste; vortex; autoclave; construction materials

\section{Introduction}

Waste generation is an unavoidable by-product of human activities. Approximately 3.5 million tonnes of municipal solid waste (MSW) are generated daily on a global scale [1]. According to the United Nation's estimates, the current world population of 7.3 billion is expected to reach 9.7 billion by 2050 and 11.2 billion by 2100 [2]. An additional 2.5 billion people will add further pressure on the already fragile Earth's eco-system. Despite preventive measures of recovery, recycling and re-use of materials, waste generation is expected to increase. The magnitude of waste production in Australia was 2.2 tonnes per capita in 2010-2011 alone. Moreover, 60\% of this generated waste was either recovered or recycled, with the remaining $40 \%$ sent for disposal in landfills [3].

Landfills emit gases and leachate into the environment and waterways as the waste is degraded over time. This will have adverse effect on the ecological system. It is estimated that landfills contribute to about $20 \%$ of the global greenhouse gas (methane and carbon dioxide) emissions and leaching of toxic chemicals, such as mercury, arsenic, beryllium, boron, cadmium, lead, thallium and hydrocarbon compounds, into the environment [1,2]. These emissions pose harmful threats to both human health and the environment [3,4]. Furthermore, landfills cause nuisances, such as flies, odours, smoke and noise, while the increase in vermin surrounding landfills becomes an issue with other adverse health effects, such as birth defects, respiratory illnesses and even cancer [5,6]. 


\subsection{Issues Related to Waste-to-Energy Treatment}

Waste-to-energy (WTE) is a commonly adopted approach, which refers to the recovery of heat and power from waste (non-recyclable waste) through combustion-based processes [4]. Despite being an attractive option for the management of MSW, it is the subject of argument and concerns $[5,6]$. The main issues relate to the absence of standard controls and the emission of harmful pollutants into the air, land and water, which in turn cause human health and environmental issues [7]. There are many recently published reports around the world discussing the results of life-cycle assessments of air pollution control, energy recovery in waste incineration and approaches to reduce their environmental impact [8-13]. It mostly acknowledges that the incineration of the unrecyclable part of MSW is the preferred management option when compared with landfilling even when waste incinerator systems produce toxic ash and other residues that need to be managed.

WTE or waste volume reduction results in the generation of mostly inorganic ash residues, which contain heavy metals, acids and other toxic compounds [14]. Environmental pollution from particulate and gaseous discharges can occur if safe ash disposal methods are not in place $[15,16]$. It is a costly practice to store large volumes of toxic ash in a landfill. Some studies have even suggested that it is important to prevent heavy metal-rich wastes from being incinerated to reduce the content of toxic metals in the fly ash [15]. The current disposal cost of MSW "tip fee" per tonne of waste in a United States (U.S.) landfill is about \$55 [17]. However, this figure does not account for the long-term cost to the environment. The major impacts of ash disposal on terrestrial ecosystems include the leaching of toxic substances into soils and groundwater, reductions in plant establishment and growth due to adverse chemical characteristics of the ash, changes in the elemental composition of vegetation growing on the ash and increased mobility and accumulation of potentially toxic elements throughout the food chain [18].

In view of the points raised above, we propose that MSW be used as a cheap and widely available raw ingredient in construction materials. In doing so, waste must be treated to a level of consistency that makes it possible to be used as a construction material. A detailed description of the MSW 'treatment process' to direct MSW to construction is provided in this paper. A holistic approach to the waste problem would consider the entire cycle of material use, which includes production, distribution and consumption, as well as waste collection and disposal $[19,20]$. Here, MSW intended for 'disposal' is diverted from a landfill or WTE and is used as the starting materials. Critics of MSW-to-construction would point to the variability in source and the difficulty in achieving consistency in the material composition. The proposed 'treatment process', however, will bring the waste product to a near-uniform consistency in terms of particle shape, size and moisture level. With regard to the variability in material composition, other products such as MSW incineration bottom ash with equally variable source materials have successfully been considered for inclusion in concrete [21-23].

\subsection{Waste Composition}

In Australia, construction and demolition waste (masonry material), organic wastes and fly ash are the largest waste streams, representing nearly two-thirds of waste generated in 2014-2015 [24]. Organic waste constitutes more than $45 \%$ of the average composition of MSW in more than 110 countries surveyed worldwide. If one excludes recyclable waste materials, such as paper $(16.7 \%)$, plastic $(10.1 \%)$, glass $(4.7 \%)$ and metals $(4.2 \%)$, organic waste, together with other "unidentified" waste $(17.7 \%)$, constitutes more than two-thirds of MSW by composition. Other countries have similar numbers. For instance, the organic matter content of China's MSW exceeds $60 \%$, and the water content is about $50 \%$ [25]. In India, analysis of MSW samples collected from a dumpsite consisted of $36 \%$ (by weight) bio-waste (food waste, yard waste, coconut waste) and around $30 \%$ recyclable materials (plastics, paper, cardboard and metals) [26]. The analysis of old MSW samples collected from the same site but different depths (3-4 $\mathrm{m}$ and 6-7 $\mathrm{m}$ ) showed the dominance of plastics $(25 \%-33 \%)$ and mixed 'organic' residue (28\%-55\%) [26]. In neighbouring Bangladesh, food and vegetable wastes are the main components (79\% on average) of MSW [27]. An investigation of a total number of 160 Egyptian 
MSW samples indicated an average percentage composition of $54.4 \%$ food waste (organic) waste [28]. Biodegradable waste in European Union member states ranges from 19\% in the United Kingdom (UK) to $49 \%$ in Greece [29]. Therefore, clearly, more than half of MSW in most countries can be classified as semi-organic, which is, at this time, either incinerated or dumped into landfills.

In the following sections, we will firstly review the published works on the use of waste in construction materials (WTC). As it will be noted, industrial waste with highly variable composition has already been used as a raw material for construction materials. Secondly, we will describe a 'treatment process' to achieve the level of consistency needed for use as a part of construction materials. In sum, the treatment process includes a sanitising procedure and an automatic separation process of different types of recyclable materials. The appropriate waste product is then subjected to vortex-oscillation technology that will offer new physical effects in the form of dehydration, grinding and mixing via an efficient and cost-effective manner [30]. Lastly, to demonstrate the feasibility of using the non-recyclable MSW (referred to as 'biomass'), a random 'treated' sample of the material is characterised and then used as a part replacement for binder in a cement paste. Calorimetry of the mixes is then carried out, followed by compressive strength testing of the cement-based biomass samples.

\section{Review of Waste to Construction: State of the Art}

The principle of waste valorisation, circular economy and recycling organic waste is relevant to both developing and advanced economies with respect to answering their current waste management issues [31]. It is expected that, with the growing population and increased rate of agricultural productivity [32], the organic waste supply will be ever more present. The interest in turning agricultural by-products (organic waste) into construction material is, however, nothing new [33-37]. There are many agri-waste-based building products that have successfully made their way into the construction industry [35,37-39], and the research and development in the area are continuing [39]. A comprehensive review of supplementary cementitious materials originating from agricultural waste is reported in [35]. Further, Akhtar and Patel [39] present a pertinent review of agro-industrial discards and invasive weed-based lignocelluloses as green building materials. Madurwar et al. [40] has equally presented a thorough review of the application of agro-waste in sustainable construction materials. The reader is encouraged to refer these recently published review papers for a detailed report on the status of research conducted on solid waste (including organic waste) intended as a construction material.

\subsection{Typical Waste Materials Investigated}

Progress in structural design and materials technology along with serious environmental concerns necessitate the use of composite materials that are lightweight, eco-friendly, cost effective and meet construction material requirements $[40,41]$. These include material workability, strength, durability, thermal properties and acoustic insulation properties. Typical waste materials that have been investigated include rice husk [37], ground coffee waste [42], banana skin [34], coconut shell [38], coconut (Cocos nucifera) and durian (Durio zibethinus) fibres [43], wood fibre waste [44,45], cellulose primary sludge generated on paper and pulp mills [46], lignocellulite waste [47], sisal fibres [48], wool fibres [49] and carpet fibre [50]. Some investigators have considered human hair fibre [51] as additive cement-based products to improve the engineering properties of construction materials [51,52].

\subsection{Typical Dosage of Waste as a Part Replacement of Raw Aggregates in Cementitious Mixes}

The dosage of organic/semi-organic product into the cementitious matrix depends on the chemical and material characteristics of the waste product. It also depends on the construction material to be produced and its desired properties. Wolfe and Gjinolli [46] verify the possibility of producing fibre-cement sheets by replacing $25 \%$ of the conventional used virgin long fibre by primary effluent treatment cellulose sludge. Some researchers pre-treat the fibre wastes, mechanically and/or chemically, 
before mixing them with cement and the appropriate amount of water [47]. The waste treatment is done to reduce the tendency of fibres to absorb water and consequently overcome the side effects of exposing the composite end-product to humidity. Different chemical treating agents, based on organic and inorganic materials, are used, e.g., gelatine-hexamine mixture, sodium silicate and linseed oil [47].

\subsection{Effect of Addition of Waste into Binder}

Experimental findings show that, in general, the addition of semi-organic or organic materials results in the decrease of workability and density of cement-based products [50]. Consequently, their mechanical properties, such as modulus of elasticity and compressive strength decrease with the increased dosage of waste content [53-55]. The decrease in strength with the increase in fibre content is due to the fact that fibres have a comparatively lower density, and some can appear as voids in comparison with the parent material [55]. Depending on the binder material and intended use, some authors have reported that some fibres increase the strength and stiffness of the mixture, thus making it a good material for construction [51].

Waste fibres, however, significantly improve the splitting tensile strength, fracture energy and cracking behaviour [48]. The reason for the improved tensile strength is the bonding interaction between the fibre and the binder matrix. When enough fibres are present in the matrix, the level of ductility and the post-cracking performance of the material is expected to improve. It is demonstrated that the peak strength may exceed the strength at first cracking by a factor of two or more, depending on the volume fraction of fibres and their strength [48]. Some explanation of the bonding and microstructural behaviour (under load) of wood fibre-reinforced cement products and their performance in service is presented in [56]. It is also commonly known that adding organic fibres improve other material properties, such as thermal properties and acoustics.

\section{Proposed MSW Treatment Process}

A method for stabilising physically unstable organic wastes comprised of non-biological, organic, water insoluble compounds, usually dispersed in water, was proposed a while back [57]. The intention was to form environmentally acceptable, impermeable, load-bearing materials [58,59]. However, the progress in this area has been slow because of the labour-intensive nature of the work and the cost associated with its treatment. The variability in the material quality, difficulty of using established manufacturing practices [59] and the odour due to volatile sulfuric compounds [60,61] have been some of the hurdles. The construction industry finds it difficult to uptake raw materials with variability in their compositions and material contamination [62,63]. Naturally, the variability in the composition of the material brings about uncertainty and increases the level of risk in successfully completing the construction work. This clearly becomes a management issue, which the builders and contractor would like to avoid. Therefore, it is less troublesome to deal with organic waste by landfilling and composting [64] rather than recycling and re-use.

There are two stages of the treatment process: the first stage essentially consists of cutting, sterilising and sorting, and the second one is composed of the grinding, mixing and drying processes.

Stage 1: Cutting, Sterilising and Sorting

Figure 1 presents the innovative processes involved in stage 1. Essentially, MSW is transferred to a 'dirty zone' using waste collection trucks. The reader should note that the process for treatment of waste retrieved from landfills is essentially the same. An example of an established process as described in stage 1 has recently been published on Australian Broadcasting Corporation (ABC) news' website [64]. 


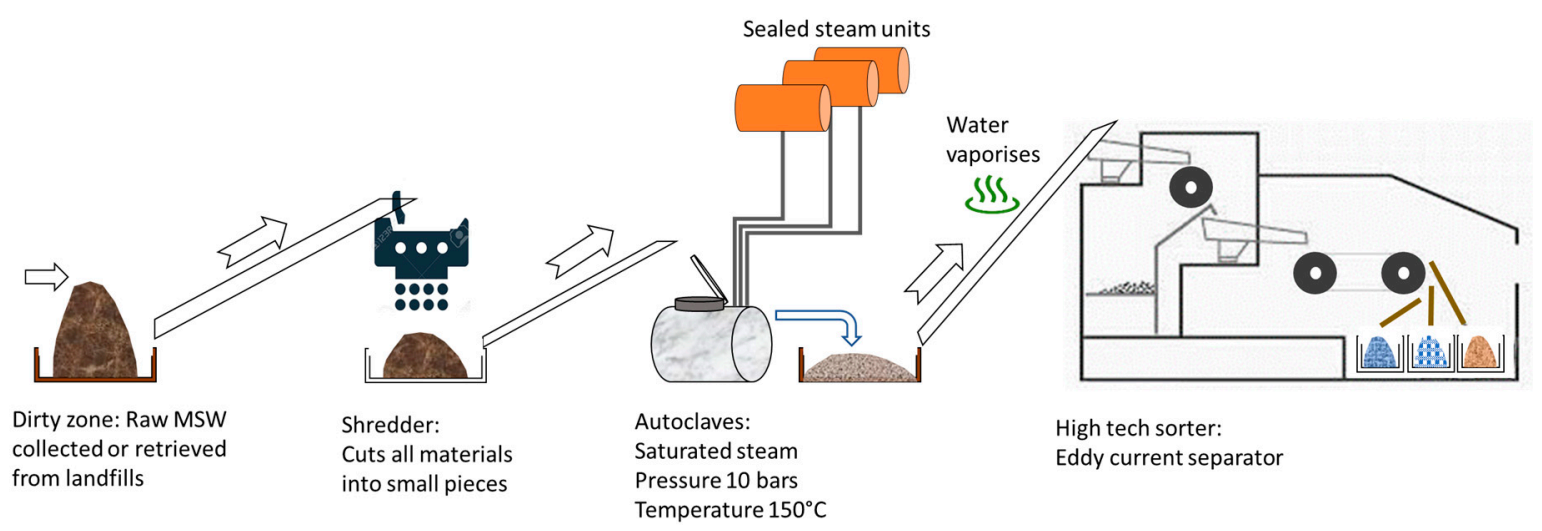

Figure 1. Autoclave-based sterilising and sorting system for treatment of municipal solid waste (MSW).

MSW is transferred via conveyor belts to a shredder, which cuts the materials to smaller size for easier manipulation and further processing. The shredded material is then transferred to steam autoclave router machines. The purpose of autoclaving MSW is to physically treat it before processing. The autoclave system operates under conditions of saturated steam with the pressure reaching 5 bars or $0.5 \mathrm{MPa}$ and temperatures up to $150^{\circ} \mathrm{C}$. Under these conditions, the microorganisms or their spores are eliminated. Background to the autoclave process is provided in $[65,66]$. The invention of the autoclave steriliser is attributed to Charles Chamberland in 1879. The process described here is similar to that used to sterilise and sort medical waste [67]. For sterilisation purposes, the steam is generated in separate steam units that are completely sealed. This means that no water is released into the environment at this stage. Because the material's biodegradable fraction undergoes physical changes, it becomes easier for various elements to separate. In addition, because sludge is separated in the process settling down, the final volume of MSW is significantly reduced. Once out of the autoclaving process, MSW is still hotter than the surrounding environment and while it is transferred to other units for further sorting, the sterile water evaporates, leaving the material semi-dry. Thereafter, MSW is transferred through the feeder to technologically advanced separators. These separators use advanced sensing technology and optics to identify different materials. The metals, plastics and glass are separated, respectively, for recycling. The end-product, which is a semi-organic mixture referred to as the 'biomass', is collected. Therefore, the separation of the recyclable part of MSW leaves the mostly organic or semi-organic portion of the waste to be treated.

Stage 2: Grinding, Mixing and Drying

The second stage consists of subjecting the appropriate waste material to vortex-oscillation technology, which offers additional physical effects, such as dehydration, grinding and mixing through an efficient and cost-effective manner. The technology is currently in demand in most manufacturing industries that require making products to a uniform consistency. Attempting to turn any waste materials and industrial by-products into a raw construction material requires consistency in material composition, particle size distribution and moisture content [27]. There are already automated systems in place for drying, mixing and grinding products in different industries, such as in cement manufacturing and agribusiness. However, advanced vortex-oscillation technology is a device that mechanically generates powerful vortices, acoustic shock, cavitation and pressure differentials in new generation equipment that is highly-efficient with low energy input, proven commercial reliability and relatively inexpensive costs [68].

The system is based on the effect of a wavy flow on the motion of a particle (waste) in air. The flow waviness decreases the hydrodynamic or aerodynamic drag and generates a forward thrust. The physics of this phenomenon are reported by Platzer and Sorokodum [69]. The apparatus for granulating materials without any grinding is well known. The working principle for this is well described in [70]. In such an apparatus, the air stream at high pressure, together with the material to be granulated, is fed into a cyclone chamber. A vortex formed within the chamber entraps the 
material and subjects it to violent turbulence, thereby causing it to break up through collision and self-abrasion. However, the apparatus as described in [68] is capable of processing very hard materials efficiently whilst minimising wear of the fan and the walls of the conduit. It creates a cyclone in air stream passing through a conduit of circular section. The centripetal forces created by the motion of the air stream pull any particulate material entrained in the air stream away from the walls of the conduit. With a wide range of sonic frequencies within the conduit, a pattern of powerful vortices is created in the air stream. The formation of regions of space with high vorticity is characterised by a high dissipation of kinetic energy. Due to the conversion, potential-to-kinetic energy stresses are created within the cyclone at the particle level, which causes minute explosions. The vortices of the cyclone take the form of implosions, which can break the material up further into smaller particles.

A schematic drawing of a typical vortex-oscillation system housed in a sound proof container box and other components are presented in Figure 2. The nature of the machine is such that it produces significant noise that can be more than $120 \mathrm{~dB}$. To enable the use of such a machine in general commercial applications and bring the noise level down to about $85 \mathrm{~dB}$, it is housed in an aero-acoustic processing machine surrounded by at least one layer of noise attenuation materials [71]. The housing is equipped with an air impeller to draw air and material to be processed through an axial inlet system, expelling the air and processed material through a transverse outlet or exhaust port for outputting processed product with air. The airflow paths that are required for the operation of the aero-acoustic processing machine are provided to enable airflow into the housing whilst significantly reducing the noise emission [71]. The untreated/raw material is fed into the system through a conveyor belt to an inlet opening located at the top of the container. The pulverised material then falls under self-weight though a narrow opening where it is collected in boxes.

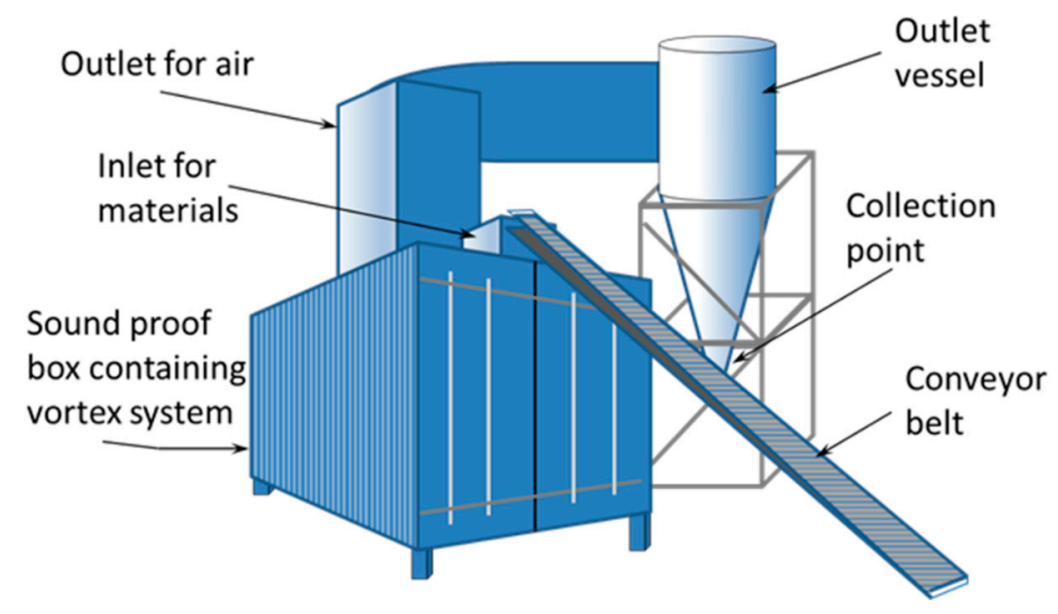

Figure 2. Typical transportable vortex-oscillation technology.

\section{Materials and Methods}

\subsection{Biomass Characterisation Methodology}

For the work presented herein, the manufacturer for the vortex machine used for biomass processing is Vortex Industrial Solutions Ltd. at Kilsyth [71]. Operating with the latest impeller design and electrical control configuration, the vortex peak efficiency for processing biomass is reached at $3300 \mathrm{rpm}$ driven by a $500 \mathrm{kw}$ electric motor drawing 44,000 cubic feet per minute $\left(1246 \mathrm{~m}^{3} / \mathrm{min}\right)$ through the processing inlet.

\subsubsection{Chemicals}

All chemicals used were purchased from Sigma-Aldrich Chemicals Co. The chemicals were of analytical reagent (AR) grade and were used without any further purification. Throughout the 
chemical synthesis, Sartorius Stedim Biotech S.A (Model-Arium 61316) deionised water (18.2 M $\Omega . c m)$ was used.

\subsubsection{Characterisation Techniques}

The vortex-processed biomass sample was characterised for its elemental contents using wavelength dispersive X-ray fluorescence (WD-XRF), which was conducted on a Bruker S4 pioneer X-ray spectrometer. Gas chromatography-mass spectrometry (GC-MS) was performed on a CP-3800 Saturn 2200 GC-MS with a polar column operated at maximum of $250{ }^{\circ} \mathrm{C}$ with a $10{ }^{\circ} \mathrm{C} / \mathrm{min}$ ramp rate. The column was an Agilent HR-GC column (DB-VRX) with a $30 \mathrm{~m}$ length, $0.25 \mathrm{~mm}$ diameter and $1.4 \mu \mathrm{m}$ wall thickness. The sample was first digested in dichloromethane (DCM) and then in hexane. The mass spectra data were analysed using National Institute of Standards and Technology (NIST) library match (NIST MS Search 2.0). A single-bounce diamond-attenuated total reflectance (ATR) attachment on a mid-infrared (MIR) was used for ATR-FTIR analysis. The instrument was a Spectrum 100 spectrometer (Perkin Elmer, Waltham, MA, USA). The scan range was set to $400-4000 \mathrm{~cm}^{-1}$ with a resolution of $4 \mathrm{~cm}^{-1}$. Approximately $0.4 \mathrm{~g}$ of the sample was used for each sample, and the scans were repeated four times across the sample before taking the mean of these results as the final value. Prior to taking a reading, the pressure applied on the diamond crystal was such that the spectral bands obtained were of high strength with a transmittance intensity of $>80 \%$. This ensured a good sample/crystal interface contact. The moisture content was determined by placing $0.766 \mathrm{~g}$ of the sample at $105^{\circ} \mathrm{C}$ for $24 \mathrm{~h}$ and observing the mass difference therein. The ash content of the sample was determined through heating the sample to $750{ }^{\circ} \mathrm{C}$ for a period of 3 and $10 \mathrm{~h}$ in air and recording the mass difference at each timepoint. To find out the content of the material that would degrade and leave the sample in the presence and absence of oxygen, thermal gravimetric analysis (TGA) was performed under both nitrogen and air atmospheres, using a Perkin Elmer Hyphenated TGA instrument. X-ray diffraction (XRD) was performed using the D8 Advance (from Bruker) with a $\mathrm{Cu}$ K-alpha radiation source $(\lambda=0.154 \mathrm{~nm})$. The XRD patterns were collected over a $2 \theta$ range of $10-80^{\circ}$ with a step size of $0.02^{\circ}$ and step time of $1 \mathrm{~s}$ per point. In order to determine how much metal actually leached out of the sample and into the acid, $195 \mathrm{mg}$ of the sample was dissolved in aqua regia solution (1:3 volume ratio of concentrated acids of $\mathrm{HNO}_{3} / \mathrm{HCl}$ ) for a $24 \mathrm{~h}$ period. The soluble metal/oxide content of the sample was estimated using a microwave plasma atomic emission spectrometer (MP-AES) system (4200 MP-AES, Agilent). The $\mathrm{pH}$ and conductivity measurements were conducted by first dissolving $0.5 \mathrm{~g}$ of solid in $25 \mathrm{~mL}$ of water followed by probe measurements. Calorimetry was performed with a calorimeter to measure the heat generated from the sample when undergoing a combustion reaction. Approximately $0.53 \mathrm{~g}$ of the sample was combusted.

\subsection{Experiments on Biomass Paste}

\subsubsection{Isothermal Calorimetry}

The biomass processed by the vortex was further mixed with reference cement to produce paste samples for testing. The hydration of the pastes containing biomass was investigated by monitoring the hydration heat using a TAM Air 8-channel isothermal calorimeter. The testing samples were cement pastes with a vortex-processed biomass replacement ratio of $0 \%, 10 \%, 15 \%$ and $20 \%$. Details of the reference cement are provided in the following section. They were prepared according to the mix proportions in Table 1. Note: The total binder is considered to be the total amount of reference cement and biomass in the paste. 
Table 1. The mix proportions of biomass (BM) based pastes for isothermal calorimetry.

\begin{tabular}{cccccc}
\hline & Reference Cement (g) & Biomass (g) & Total Binder (g) & w/b & Water (g) \\
\hline Ref & 30.0 & 0.0 & 30.0 & 0.44 & 13.2 \\
\hline $\mathbf{1 0} \% \mathbf{B M}$ & 27.0 & 3.0 & 30.0 & 0.44 & 13.2 \\
\hline $\mathbf{1 5} \% \mathbf{B M}$ & 25.5 & 4.5 & 30.0 & 0.44 & 13.2 \\
\hline $\mathbf{2 0} \% \mathbf{B M}$ & 24.0 & 6.0 & 30.0 & 0.44 & 13.2 \\
\hline
\end{tabular}

As the hydration heat was captured by the isothermal calorimeter under a constant temperature of $23{ }^{\circ} \mathrm{C}$, all the materials before mixing were kept in the room at a temperature of $23^{\circ} \mathrm{C}$ for $24 \mathrm{~h}$. The cement pastes were manually mixed by using a wooden stick for $7 \mathrm{~min}$. Immediately after the mixing of each sample, the sample was injected into a glass ampoule with a cap on and loaded into the calorimeter. The calorimeter measured the hydration heat and heat flow continuously over time until it was stopped after $90 \mathrm{~h}$ from the loading of samples.

For comparison between the different samples, the recorded hydration heat and heat flow of each sample were normalised by dividing by the total mass of dry materials. The maximum heat of hydration for each sample was found at the time when the heat flow became stable and close to zero. The difference of hydration heat between the reference cement and each paste sample divided by the hydration heat of the reference cement paste was calculated as the reduction percentage compared with the reference sample.

The experiments in this research used reference cement supplied by Cement Australia. The chemical composition and the particle size distribution of the reference cement are presented in Table 2 and Figure 3, respectively. The biomass fibre provided by Bioelectra Pty Ltd. was processed by the vortex machine. The material properties of the biomass fibre are presented in Section 5.

Table 2. The chemical composition of the reference cement.

\begin{tabular}{cccccccccc}
\hline Composition & $\mathrm{LOI}$ & $\mathrm{SO}_{3}$ & $\mathrm{CaO}$ & $\mathrm{SiO}_{2}$ & $\mathrm{Al}_{2} \mathrm{O}_{3}$ & $\mathrm{Fe}_{2} \mathrm{O}_{3}$ & $\mathbf{M g O}$ & $\mathbf{K}_{2} \mathrm{O}$ & $\mathbf{N a}_{2} \mathrm{O}$ \\
\hline $\mathbf{( \% )}$ & 3.9 & 2.7 & 63.7 & 19.9 & 4.6 & 2.57 & 1.39 & 0.69 & 0.09 \\
\hline Composition & $\mathbf{P}_{\mathbf{2}} \mathrm{O}_{5}$ & $\mathrm{Mn}_{2} \mathrm{O}_{3}$ & $\mathrm{Cr}_{2} \mathrm{O}_{3}$ & $\mathrm{SrO}$ & $\mathrm{Na}_{2} \mathrm{O}$ & $\mathrm{C}_{3} \mathrm{~S}$ & $\mathrm{C}_{3} \mathrm{~A}$ & $\mathrm{C}_{4} \mathrm{AF}$ & \\
\hline$(\%)$ & 0.04 & 0.06 & 0 & 0.07 & 0.5 & 65.78 & 7.82 & 7.88 &
\end{tabular}

Note: $\mathrm{C}_{3} \mathrm{~S}$ is tricalcium silicate $(\mathrm{CaO})_{3} \mathrm{SiO}_{2} ; \mathrm{C}_{3} \mathrm{~A}$ is tricalcium aluminate $(\mathrm{CaO})_{3} \mathrm{Al}_{2} \mathrm{O}_{3} ; \mathrm{C}_{4} \mathrm{AF}$ is tetracalcium aluminoferrite $(\mathrm{CaO})_{4} \mathrm{Al}_{2} \mathrm{O}_{3} \mathrm{Fe}_{2} \mathrm{O}_{3}$.

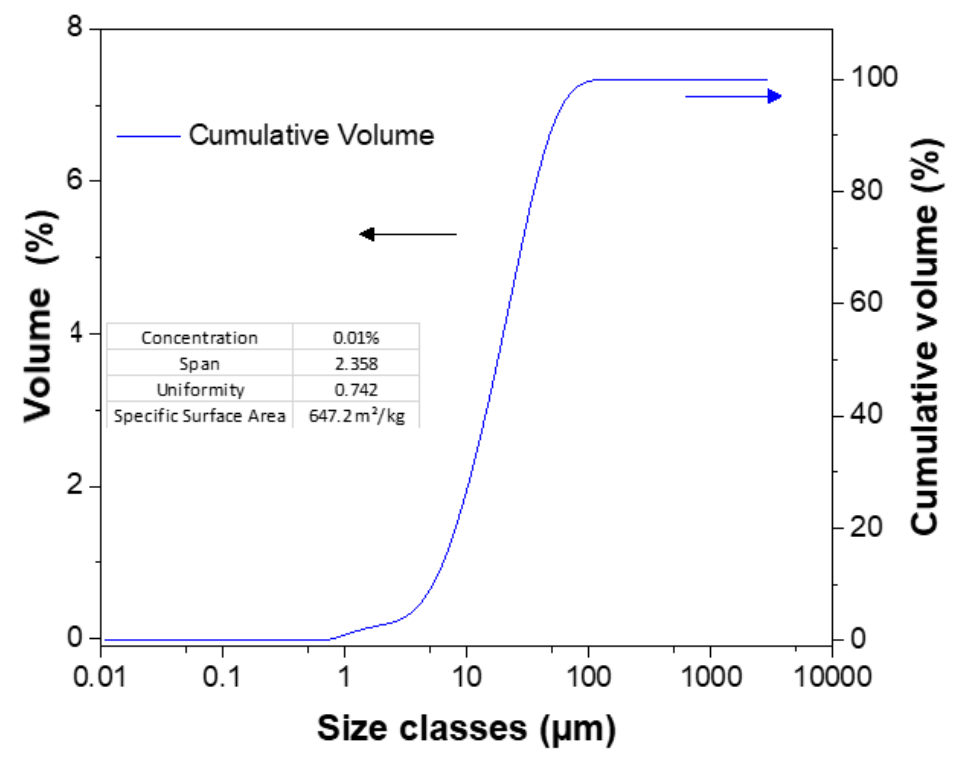

Figure 3. The particle size distribution of the reference cement. 


\subsubsection{Mechanical Testing}

The compressive strength testing was conducted at 7, 14 and 28 days by using a Technotest compression testing machine. Cement cubes of $50 \mathrm{~cm} \times 50 \mathrm{~cm} \times 50 \mathrm{~cm}$ were prepared for the testing based on the mix design presented in Table 3. Vortex-processed biomass was used to replace the reference cement by $0 \%, 10 \%, 15 \%$ and $20 \%$, respectively, in the mixes.

Table 3. The composition of biomass (BM) based pastes for compressive strength testing.

\begin{tabular}{ccccccc}
\hline & $\begin{array}{c}\text { Reference Cement } \\
(\mathbf{g})\end{array}$ & Biomass (g) & Total Binder (g) & $\mathbf{w / b}$ & Water (g) & SP (g) \\
\hline Ref & 1000 & 0.0 & 1000 & 0.44 & 441.2 & 0.0 \\
\hline $\mathbf{1 0} \% \mathbf{B M}$ & 900 & 100.0 & 1000 & 0.44 & 441.2 & 8.0 \\
\hline $\mathbf{1 5} \% \mathbf{B M}$ & 850 & 150.0 & 1000 & 0.44 & 441.2 & 12.0 \\
\hline $\mathbf{2 0} \% \mathbf{B M}$ & 800 & 200.0 & 1000 & 0.44 & 441.2 & 16.0 \\
\hline
\end{tabular}

\section{Results}

\subsection{Optical Characterisation}

The optical image of the vortex-processed biomass (VPB) sample is shown in Figure 4. It can be observed that VPB is a fibrous material in the micrometre-to-millimetre size range. Due to the organic contents and fibrous nature of VPB, no electron microscope characterisation could be performed.
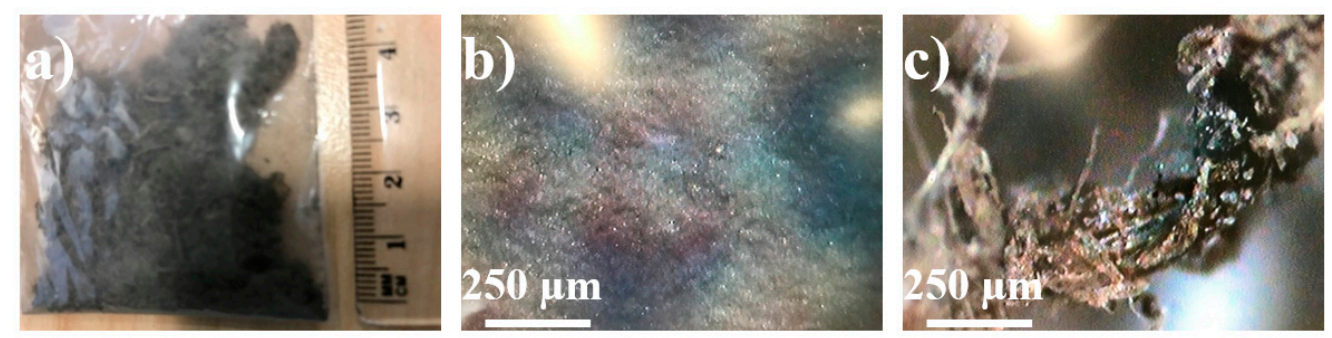

Figure 4. Optical microscope image of (a) vortex-processed biomass (VPB) sample in a plastic bag, (b) VPB sample on white paper and (c) higher magnification of the biomass material on paper.

\subsection{Elemental/Oxides Analysis}

The VPB sample was characterised for its elemental contents using WD-XRF. The data obtained is shown in Table 4. 
Table 4. X-ray fluorescence (XRF) data showing elemental analysis of the biomass when considered in both elemental and oxide forms.

\begin{tabular}{|c|c|c|c|}
\hline Formula & Oxide Formula & $\mathbf{Z}$ & Concentration $(\%)$ \\
\hline $\mathrm{Na}$ & $\mathrm{Na}_{2} \mathrm{O}$ & 11 & 0.36 \\
\hline $\mathrm{Mg}$ & $\mathrm{MgO}$ & 12 & 0.26 \\
\hline Al & $\mathrm{Al}_{2} \mathrm{O}_{3}$ & 13 & 0.46 \\
\hline Si & $\mathrm{SiO}_{2}$ & 14 & 2.73 \\
\hline $\mathbf{P}$ & $\mathrm{P}_{2} \mathrm{O}_{5}$ & 15 & 0.29 \\
\hline$S$ & $\mathrm{SO}_{3}$ & 16 & 0.42 \\
\hline $\mathrm{Cl}$ & - & 17 & 0.89 \\
\hline $\mathbf{K}$ & $\mathrm{K}_{2} \mathrm{O}$ & 19 & 1.22 \\
\hline $\mathrm{Ca}$ & $\mathrm{CaO}$ & 20 & 10.44 \\
\hline $\mathrm{Ti}$ & $\mathrm{TiO}_{2}$ & 22 & 0.21 \\
\hline $\mathrm{Cr}$ & $\mathrm{Cr}_{2} \mathrm{O}_{3}$ & 24 & 0.13 \\
\hline Mn & $\mathrm{MnO}$ & 25 & 0.44 \\
\hline $\mathrm{Fe}$ & $\mathrm{Fe}_{2} \mathrm{O}_{3}$ & 26 & 3.36 \\
\hline $\mathrm{Ni}$ & $\mathrm{NiO}$ & 28 & 0.01 \\
\hline $\mathrm{Cu}$ & $\mathrm{CuO}$ & 29 & 0.02 \\
\hline $\mathrm{Zn}$ & $\mathrm{ZnO}$ & 30 & 0.19 \\
\hline $\mathrm{Br}$ & - & 35 & 0.01 \\
\hline $\mathbf{R b}$ & $\mathrm{Rb}_{2} \mathrm{O}$ & 37 & 0.00 \\
\hline $\mathrm{Sr}$ & $\mathrm{SrO}$ & 38 & 0.08 \\
\hline $\mathrm{Nb}$ & $\mathrm{Nb}_{2} \mathrm{O}_{5}$ & 41 & 0.01 \\
\hline $\mathbf{B a}$ & $\mathrm{BaO}$ & 56 & 0.05 \\
\hline $\mathrm{Pb}$ & $\mathrm{PbO}$ & 82 & 0.09 \\
\hline
\end{tabular}

It can be observed that VPB mostly contains $\mathrm{Si}, \mathrm{Ca}$ and $\mathrm{Fe}$, with the remaining mass being carbon-based materials. It should be noted that the absence of an element in Table 4 (except for carbon) indicates its absence in the sample. The data suggests that VPB's constituents could be ideal as a part replacement material in some construction materials.

\subsection{Organic Compound Separation}

GC-MS was performed to identify different substances that were present in the VPB sample. The two strong solvents used to extract the organic species were hexane and dichloromethane. The GC and the respective MS for some of the compounds are shown in Figure 5. There were over 14 of such substances observed in the GC data. The mass spectra for two regions (as indicated in the GC panels) are also shown. The data shows that the substances that are dissolved in each solvent have high retention times and so are expected to be of high molecular weights. Using the NIST library match (see Section 4), it was clear that the large molecular weight compounds (extracted in both DCM and hexane at times) were present in the VPB sample. 

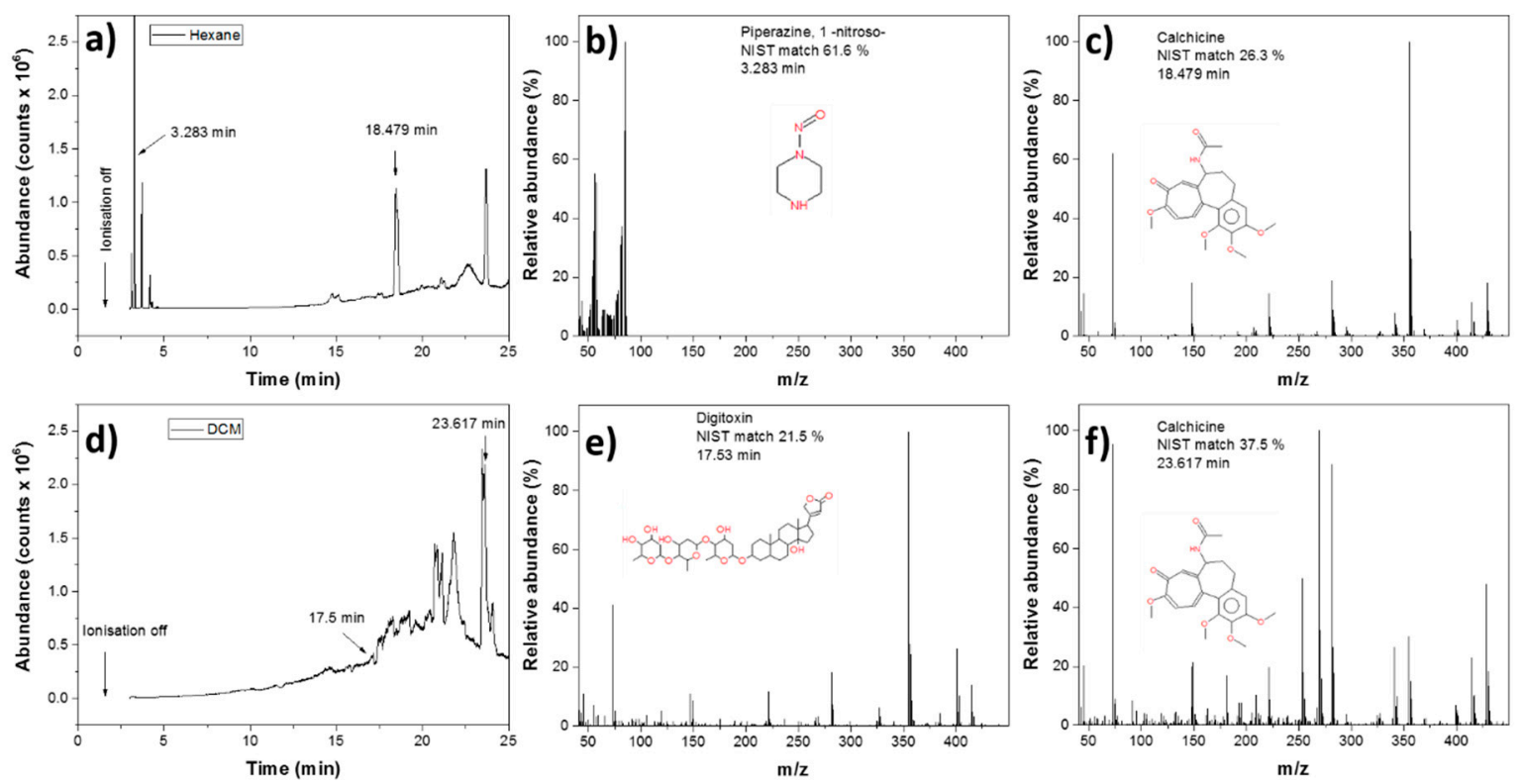

Figure 5. GC separation of the organic species (a) extracted in hexane and the respective MS at the retention times of (b) $3.283 \mathrm{~min}$ and (c) $18.479 \mathrm{~min}$. GC separation of the organic species (d) extracted in dichloromethane (DCM) and the respective MS at the retention times of (e) $17.5 \mathrm{~min}$ and (f) $23.617 \mathrm{~min}$.

\subsection{Moisture Content}

The presence of moisture in the VPB sample was confirmed through ATR-FTIR technique. Figure 6 shows the ATR-FTIR spectra of the VPB sample in which a big moisture peak observed at $3500-3300 \mathrm{~cm}^{-1}$ is attributed to moisture. The peaks at the lower wavenumbers represent substances with other functional groups. The peaks at $1020-1220 \mathrm{~cm}^{-1}$ could be attributed to alkyl amines, whereas the strong peak at $1026 \mathrm{~cm}^{-1}$ can be attributed to $\mathrm{C}-\mathrm{O}$ functional groups. The strong peak at $1420 \mathrm{~cm}^{-1}$ could be attributed to alkanes.

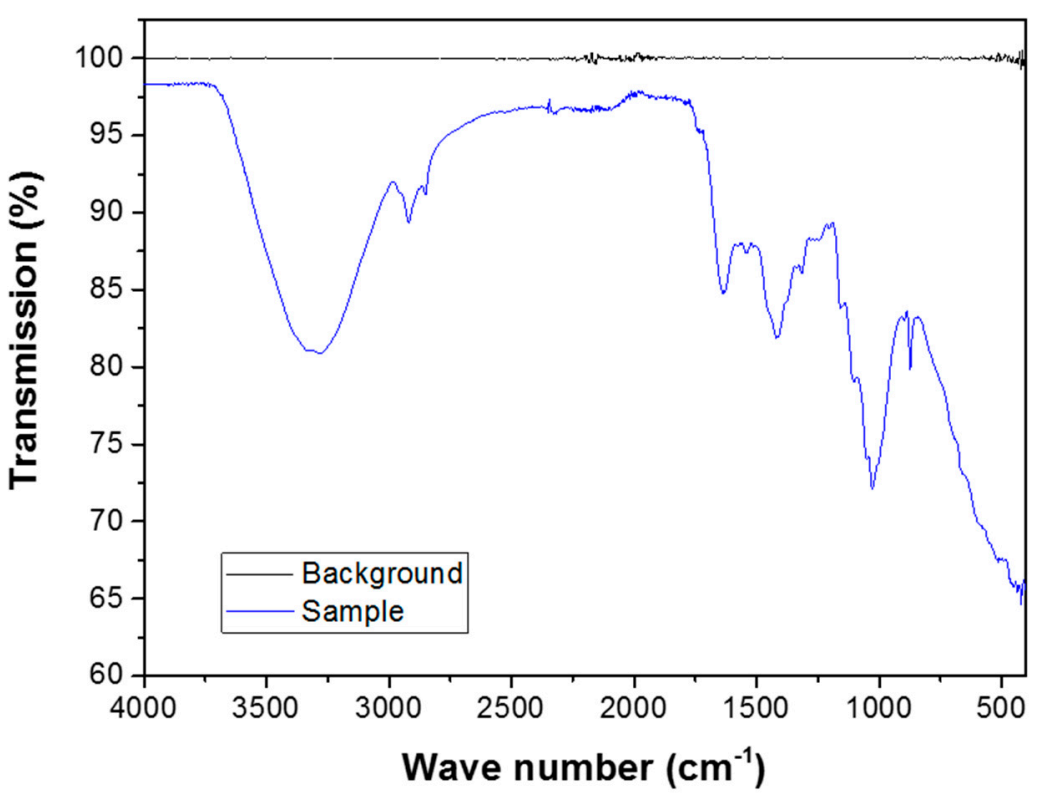

Figure 6. Attenuated total reflectance (ATR)-FTIR spectra of the sample provided.

Once the presence of moisture was confirmed, the quantity of moisture was measured by heating the sample and observing the mass difference. The data from the experiment are shown in Table 5. 
Assuming all mass lost was due to moisture (accepted in usual biomass moisture tests), then the moisture content of the VPB sample is observed to be $11.0 \%$.

Table 5. Mass difference of the sample after heating at $105^{\circ} \mathrm{C}$ for a $24 \mathrm{~h}$ period.

\begin{tabular}{cccc}
\hline Sample & Mass (mg) & Moisture (mg) & Moisture (\%) \\
\hline Crucible & 31303.0 & & \\
Crucible + sample before heating & 32068.5 & & \\
Crucible + sample after heating & 31984.0 & 84.5 & 11.0 \\
\hline
\end{tabular}

\subsection{Sample Degradation (Ash Content)}

It is expected that most volatile/organic substances would decompose at high temperatures. Therefore, the VPB sample was heated to $750{ }^{\circ} \mathrm{C}$ for $10 \mathrm{~h}$ in air to observe the amount of material that would be left behind after such an intense sintering process. The data are presented in Table 6 . It is observed that $61 \%$ of the material was decomposable, whereas the other $39 \%$ was stable even after intense heat treatments.

Table 6. Mass difference of sample after intense heating at $750{ }^{\circ} \mathrm{C}$ for a $10 \mathrm{~h}$ period.

\begin{tabular}{cccc}
\hline Sample & Mass (mg) & Decomposed Materials (mg) & Decomposed Materials (\%) \\
\hline Crucible & 31303.0 & & \\
Crucible + sample before heating & 31752.8 & & 61.0 \\
Crucible + sample after heating (3h) & 31478.2 & 175.2 & 0.0 \\
Crucible + sample after heating (10h) & 31478.2 & 0.0 & \\
\hline
\end{tabular}

To determine the content of the material that would degrade and leave the VPB sample in different conditions, TGA analysis was performed on the "as is" VPB under both nitrogen and air atmospheres, the results of which are shown in Figures $7 \mathrm{a}$ and $7 \mathrm{~b}$, respectively. To obtain a better understanding of the amount of material that decomposed off the material, the sample was "ground up" into fine particles. It was observed that the moisture content contributed to the sticking of the finer particles when the grinding process was undertaken. 

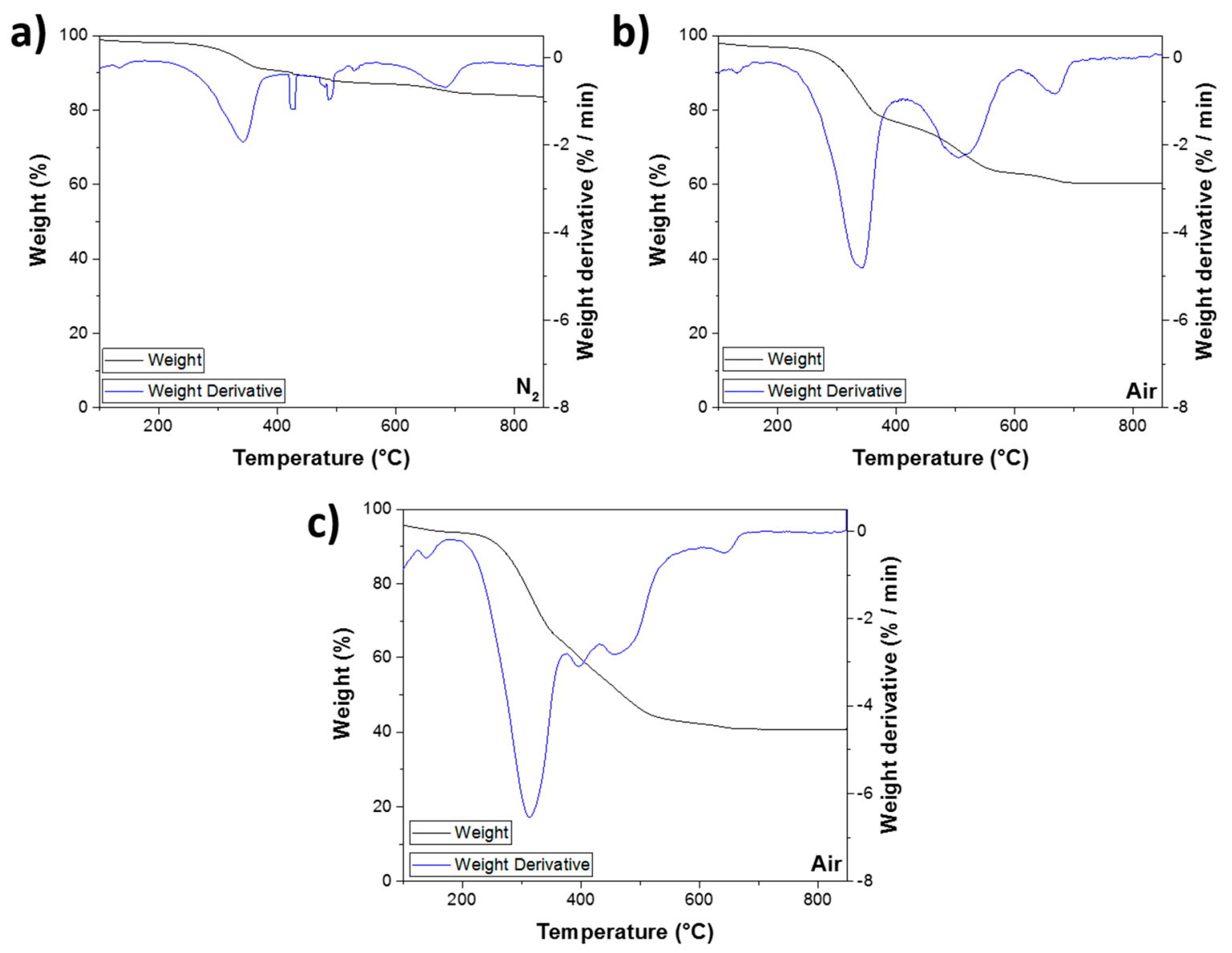

Figure 7. TGA analysis of the "as is" VPB sample under (a) nitrogen gas and (b) air atmospheres; TGA of (c) "ground up" VPB under air atmosphere.

The "ground up" VPB sample was then analysed by TGA under air. It was found that the mass loss/decomposition behaviour of the VPB sample under N2 gas was different than that under air. The mass loss under nitrogen and air were estimated at $\sim 20 \%$ and $\sim 40 \%$, respectively. In the nitrogen atmosphere, the products were formed through anaerobic reactions only due to the lack of oxygen molecules, and hence, no combustion reactions could occur. Therefore, the low rate of mass loss under the nitrogen atmosphere is attributed to the halting of the combustion reactions. This is evident when observing the TGA analysis of the ground VPB sample in Figure 7c. The higher surface area of the crushed sample allows for a higher combustion rate compared with the "as is" VPB sample due to better interaction with the oxygen molecules from the air. The derivative line (blue line with right axis) shows the temperatures at which the main mass loss occurred. It can be observed that a significant mass loss occurred between 300 and $500{ }^{\circ} \mathrm{C}$ under both nitrogen and air atmospheres.

\subsection{Crystal Components Analysis}

To determine if any crystalline material were present, the VPB sample was characterised by XRD using the Bruker D4 Endeavour system. The data are shown in Figure 8. It can be observed that crystalline substances are present in the material. The library search showed the presence of $\mathrm{CaO}$ (calcium oxide JCPDS card no: 28-0775), $\mathrm{Fe}_{2} \mathrm{O}_{3}$ (magnetite-C JCPDS card no: 39-1346) and $\mathrm{Ca}_{4} \mathrm{Fe}_{9} \mathrm{O}_{17}$ (calcium iron oxide JCPDS card no: 75-2421), in addition to other crystalline substances. 


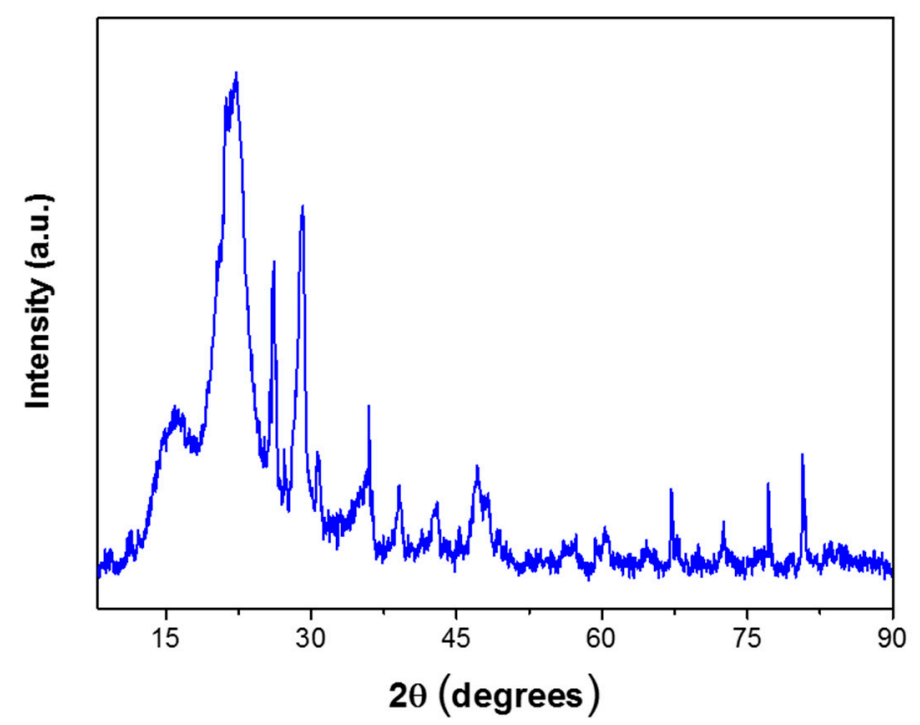

Figure 8. XRD analysis of the VPB sample.

\subsection{Proportion of Dissolvable Solids}

It is essential that suitable leachate analysis is undertaken on raw materials used for developing construction materials before large-scale production is approved.

In this study, a strong leaching acid, namely, aqua regia (1:3 concentrated acids of $\mathrm{HCl} / \mathrm{HNO}_{3}$ mixture) was used on the VPB sample for a $24 \mathrm{~h}$ period. The concentration of each metal dissolved in the mixed acid obtained from MP-AES analysis is shown in Table 7. It was found that the heavy and toxic metals concentrations were either zero or insignificant from a construction materials' safety limits point of view. This indicates that the VPB can be used as a part replacement material when developing construction materials.

Table 7. Microwave plasma atomic emission spectrometer (MP-AES) when digesting $195 \mathrm{mg}$ of sample in aqua regia for a $24 \mathrm{~h}$ period.

\begin{tabular}{cccc}
\hline Formula & Concentration Wt. $\%$ & Formula & Concentration Wt. $\%$ \\
\hline Se & 0.09 & $\mathbf{U}$ & 0.17 \\
$\mathbf{Z n}$ & 0.07 & $\mathbf{T l}$ & 0.00 \\
\hline $\mathbf{C d}$ & 0.06 & $\mathbf{T h}$ & 0.00 \\
\hline $\mathbf{V}$ & 0.01 & $\mathbf{P b}$ & 0.05 \\
\hline $\mathbf{C a}$ & 0.54 & $\mathbf{U}$ & 0.08 \\
\hline $\mathbf{A g}$ & 0.01 & $\mathbf{T l}$ & 0.04 \\
\hline $\mathbf{F e}$ & 0.16 & $\mathbf{K}$ & 0.08 \\
\hline $\mathbf{B a}$ & 0.01 & $\mathbf{M o}$ & 0.02 \\
\hline $\mathbf{N i}$ & 0.02 & $\mathbf{M g}$ & 0.08 \\
\hline $\mathbf{C u}$ & 0.02 & $\mathbf{M n}$ & 0.32 \\
\hline $\mathbf{N i}$ & 0.01 & $\mathbf{C r}$ & 0.03 \\
\hline $\mathbf{A s}$ & 0.28 & $\mathbf{M g}$ & 0.07 \\
\hline $\mathbf{S b}$ & 0.25 & $\mathbf{A l}$ & 0.26 \\
\hline $\mathbf{B e}$ & 0.00 & $\mathbf{N a}$ & 0.05 \\
$\mathbf{C o}$ & 0.04 & $\mathbf{H g}$ & 0.00 \\
\hline
\end{tabular}




\subsection{Summary of the Material Characterisation}

The material characterisation of the vortex-processed biomass (VPB) sample identified by the tests in this section is summarised and presented in the Table 8. Furthermore, the $\mathrm{pH}$ and electrical conductivity of the VPB sample was found to be 9.17 and $3.66 \mathrm{mS} / \mathrm{cm}$, respectively. The calorimetric value for VPB was found to be $12.864 \mathrm{MJ} / \mathrm{kg}$, which was a significant improvement over the value of $8.6 \mathrm{MJ} / \mathrm{kg}$, which was obtained for the biomass prior to the vortex process. The higher calorimetric value is attributed to the relatively reduced moisture content of the VPB, thus losing relatively lower energy in heating and vaporisation of the moisture content. Details are shown in Table 9.

Table 8. Summary of the results presented in this study.

\begin{tabular}{ccc}
\hline Specified Chemical/Other Attribute & Units & Concentration \\
\hline Mercury & $\mathrm{mg} / \mathrm{kg}$ & 0 \\
Cadmium & $\mathrm{mg} / \mathrm{kg}$ & 26 \\
Lead & $\mathrm{mg} / \mathrm{kg}$ & 0 \\
Arsenic & $\mathrm{mg} / \mathrm{kg}$ & 0 \\
Chromium & $\mathrm{mg} / \mathrm{kg}$ & 13 \\
Copper & $\mathrm{mg} / \mathrm{kg}$ & 2 \\
Nickel & $\mathrm{mg} / \mathrm{kg}$ & 1 \\
Selenium & $\mathrm{mg} / \mathrm{kg}$ & 0 \\
Zinc & $\mathrm{mg} / \mathrm{kg}$ & 0 \\
\hline Other elements & $\mathrm{mg} / \mathrm{kg}$ & 2111 \\
$\mathbf{N a}$ & $\mathrm{mg} / \mathrm{kg}$ & 36 \\
$\mathbf{M g}$ & $\mathrm{mg} / \mathrm{kg}$ & 26 \\
$\mathbf{A l}$ & $\mathrm{mg} / \mathrm{kg}$ & 46 \\
$\mathbf{S i}$ & $\mathrm{mg} / \mathrm{kg}$ & 273 \\
$\mathbf{P}$ & $\mathrm{mg} / \mathrm{kg}$ & 29 \\
$\mathbf{S}$ & $\mathrm{mg} / \mathrm{kg}$ & 42 \\
$\mathbf{C l}$ & $\mathrm{mg} / \mathrm{kg}$ & 89 \\
$\mathbf{K}$ & $\mathrm{mg} / \mathrm{kg}$ & 122 \\
$\mathbf{C a}$ & $\mathrm{mg} / \mathrm{kg}$ & 1044 \\
$\mathbf{T i}$ & $\mathrm{mg} / \mathrm{kg}$ & 21 \\
$\mathbf{M n}$ & $\mathrm{mg} / \mathrm{kg}$ & 44 \\
$\mathbf{F e}$ & $\mathrm{mg} / \mathrm{kg}$ & 336 \\
$\mathbf{Z n}$ & $\mathrm{mg} / \mathrm{kg}$ & 19 \\
$\mathbf{B r}$ & $\mathrm{mg} / \mathrm{kg}$ & 1 \\
$\mathbf{R b}$ & $\mathrm{mg} / \mathrm{kg}$ & 0 \\
$\mathbf{S r}$ & $\mathrm{mg} / \mathrm{kg}$ & 8 \\
$\mathbf{N b}$ & $\mathrm{mg} / \mathrm{kg}$ & 1 \\
\hline
\end{tabular}

Table 9. Physical characteristics of the biomass.

\begin{tabular}{|c|c|c|c|c|c|c|}
\hline $\begin{array}{l}\text { Moisture } \\
\text { Content }\end{array}$ & $\begin{array}{l}\text { Non-Decomposed } \\
\text { Solid }\end{array}$ & $\begin{array}{c}\text { Decomposed } \\
\text { solid (Air, } 750^{\circ} \mathrm{C} \text { ) }\end{array}$ & $\begin{array}{l}\text { Crystalline } \\
\text { Substances }\end{array}$ & $\mathrm{pH}$ in $\mathrm{H}_{2} \mathrm{O}$ & $\begin{array}{c}\text { Calorimetric } \\
\text { Value }\end{array}$ & $\begin{array}{c}\text { Electrical } \\
\text { Conductivity } \\
\text { (EC) }\end{array}$ \\
\hline$\%$ & $\%$ & $\%$ & Yes/no & $\mathrm{pH}$ & $\mathrm{MJ} / \mathrm{kg}$ & $\mathrm{mS} / \mathrm{cm}$ \\
\hline 11 & 31 & 69 & yes & $9.17^{*}$ & 12.864 & $3.66^{*}$ \\
\hline
\end{tabular}

${ }^{*} \mathrm{pH}$ and conductivity were determined by dissolving $0.5 \mathrm{~g}$ of solid in $25 \mathrm{~mL}$ of water followed by measurements due to the nature of the sample.

\subsection{Heat of Hydration}

The monitored heat of hydration for cement pastes with a biomass replacement ratio of $0 \%$, $10 \%, 15 \%$ and 20\% are presented in Figures 9 and 10. Figure 9 shows the normalised heat flow, which indicates the rate of released hydration heat. There are several peaks in each heat flow curve. The first peaks of all the pastes showing high rates of hydration heat can be clearly observed in Figure $9 \mathrm{~b}$. The first peak represents the dissolution of the surface of the cement particles, mainly involving the 
hydration of $\mathrm{C}_{3} \mathrm{~A}$ (tri-calcium aluminate, $3 \mathrm{CaO} \cdot \mathrm{Al}_{2} \mathrm{O}_{3}$ ). The first peak of paste containing $10 \%$ biomass had a similar height as that of the reference cement paste. Except in that case, with the increase of the biomass percentage in the paste, the height of first peak decreased, indicating a lower rate of hydration heat.

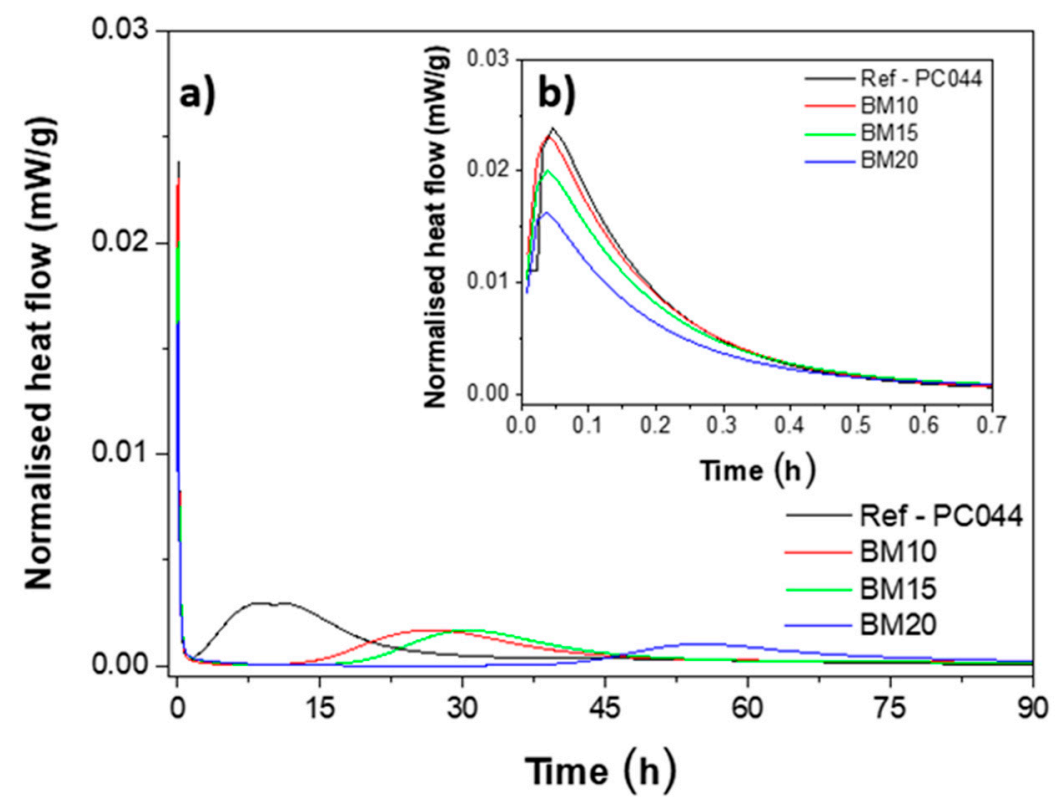

Figure 9. (a) Normalised heat flow of all the cement pastes from 0 to $90 \mathrm{~h}$; (b) normalised heat flow of all the cement pastes from 0 to $0.7 \mathrm{~h}$.

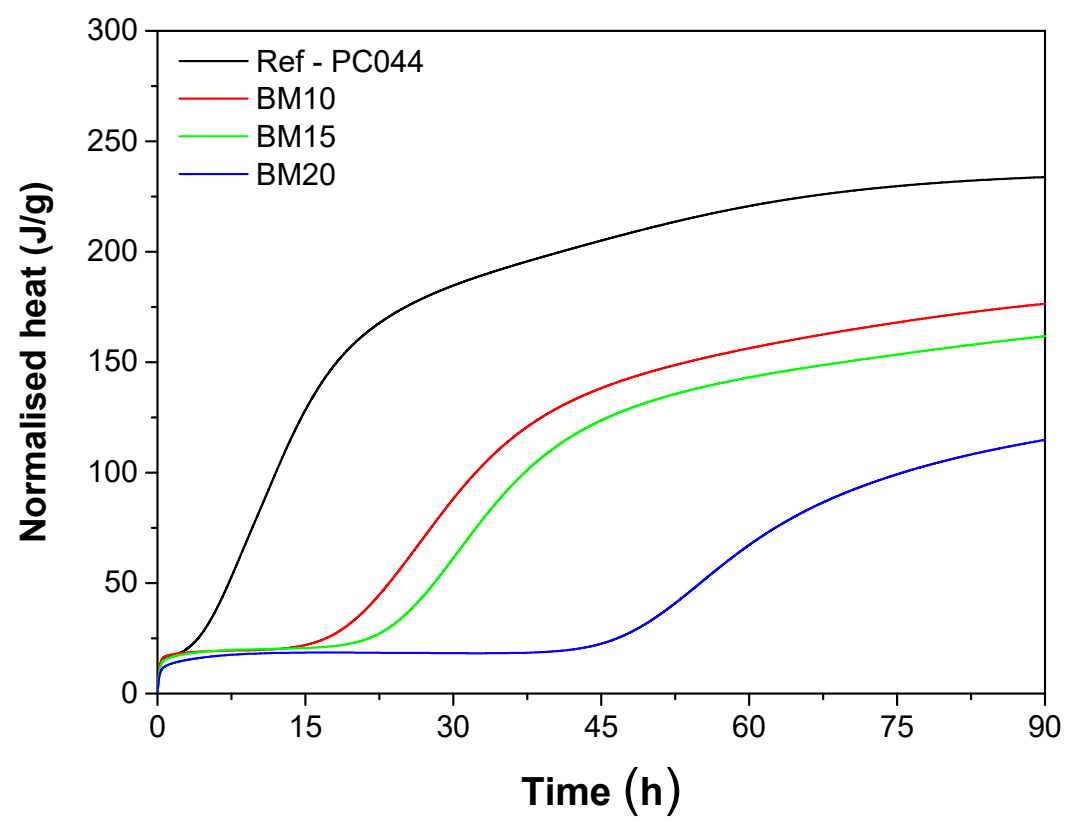

Figure 10. Normalised heat of all the cement pastes.

As can be seen in Figure 9a, the increase of biomass percentage in the paste caused more retardation of the occurrence of the second peak. As the second peak is associated with the setting of pastes, the setting of pastes was delayed with the increase of the biomass ratio. Figure 9a shows that the pure reference cement paste has a third peak following the second peak, while pastes containing biomass do not have a third peak in their heat flow curves. The heat flow curves of the cement with biomass have lower heights compared with that of reference cement paste. A higher biomass replacement level 
causes the lower height of the heat flow curve. This indicates that the increase of biomass in the cement paste could result in a lower rate of hydration during the $90 \mathrm{~h}$ from the beginning of the hydration.

Figure 10 shows the cumulative heat of hydration over time for all the pastes. The heat of hydration for pastes with biomass is much lower than that of the reference cement pastes. A higher biomass percentage contributed to the lower hydration heat. Different from the hydration heat curve of the reference cement paste, which is increasing continuously, the hydration heat curve is quite flat from 0 up to $20 \mathrm{~h}$ for pastes with $10 \%$ and $15 \%$ biomass. The heat of hydration curve for pastes with $20 \%$ biomass is nearly flat from 0 to $45 \mathrm{~h}$. This indicates that the hydration of the pastes with biomass during these periods was very slow and even was not increasing.

As the increase of hydration heat is not noticeable after 3 or 4 days of hydration, the maximum heat of hydration for all the pastes could be found and are presented in Table 10 for comparison. The hydration heat of pastes with $10 \%$ and $15 \%$ biomass was decreased up to $24.53 \%$ and $30.8 \%$, respectively. The hydration heat of pastes was reduced up to $50.88 \%$ when the biomass replacement level reached $20 \%$.

Table 10. The maximum cumulative heat for all the cement paste samples.

\begin{tabular}{ccc}
\hline Sample & Cumulative Heat $(\mathrm{J} / \mathrm{g})$ & Reduction (\%) \\
\hline Ref & 233.80 & \\
$\mathbf{1 0} \% \mathbf{B M}$ & 176.45 & 24.53 \\
\hline $\mathbf{1 5} \% \mathbf{B M}$ & 161.79 & 30.80 \\
\hline $\mathbf{2 0} \% \mathbf{B M}$ & 114.83 & 50.88 \\
\hline
\end{tabular}

\subsection{Compressive Strength Development}

The compressive strength for the reference paste (Ref) and $10 \%$ and $15 \% \mathrm{BM}$ paste samples at 7 , 14 and 28 days are presented in Figure 11. Three samples for each type of paste were tested, as indicated by the datapoints presented in Figure 11. The results show that the strength of the samples consistently increased between 7 and 28 days. The strength of the reference sample without any biomass was the highest, and its rate of increase (as indicated by the gradient of the line) was also higher. Figure 11 clearly indicates that with the addition of the biomass, the strength of the paste decreased and the rate of the strength gain was milder. This result was expected, because the volume of cement was reduced and the biomass acts as a filler. However, the biomass-based pastes exhibited a gradual drop in the applied load at failure when compared with the plain mortar, which indicates higher ductility of the material. The sample deformations and elasticity were not measured in these preliminary tests and will be the subject of follow-up work. 


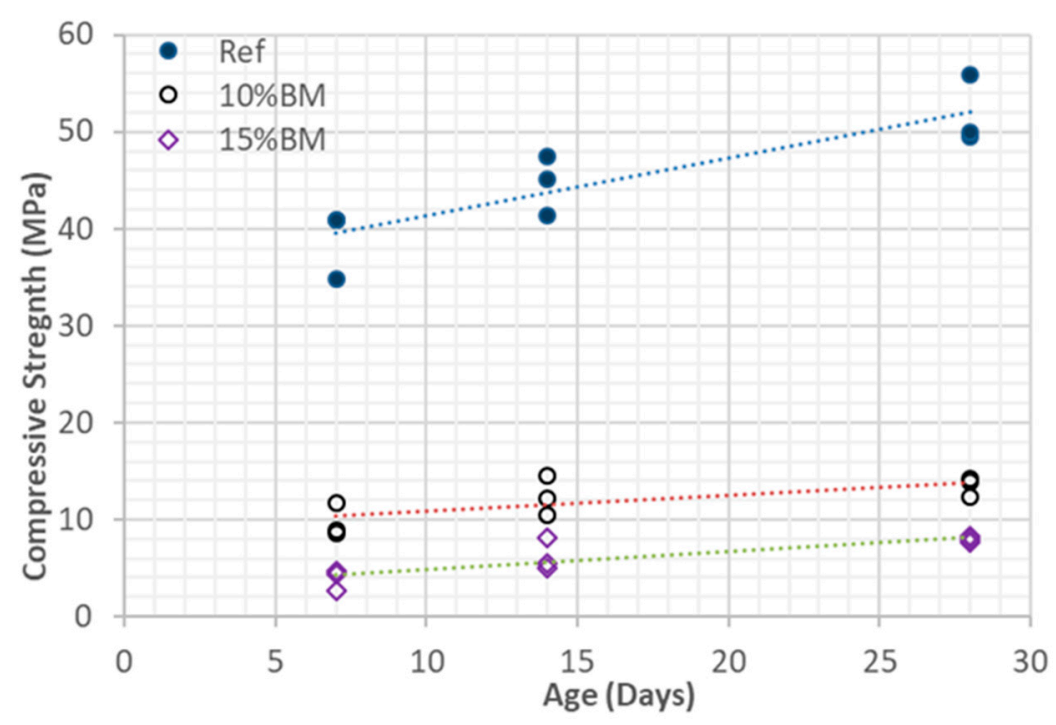

Figure 11. Compressive strength development for the reference (Ref), 10\% BM and 15\%BM pastes.

It should be noted that when the biomass replacement ratio of cement is increased to $20 \%$, the samples did not gain enough strength, even after 28 days, to be tested under compression. The material in the paste did not bind together and appeared to still be wet. It can be concluded from these observations that the maximum dosage of vortex-treated biomass that can be used in a paste is not larger than $15 \%$. The reader should note that here no extra additives were tested, nor was the purpose of the work to optimise the mix for a suitable application. This will certainly constitute the subject of future investigation.

However, the significant finding here, as depicted in Figure 11, is that the datapoints for the cement pastes containing different levels of biomass at each testing stage are very close to each other (indicating lower standard deviation) and that test results are very consistent, indicating a very small discrepancy in strength results.

The results presented indicate that with the proposed treatment process, it is possible to incorporate biomass to produce value-added materials that can be used towards construction. However, it should be noted that this paper presents exploratory investigation in which a small portion of the cement mass has been replaced by biomass. There have not been any attempts for mix-optimisation, including the use of available chemical additives to improve the engineering properties. These issues will form the basis for follow-up investigations.

\section{Implications of the Proposed Methodology and Challenges}

The two-step method prescribed herein relies on the most advanced technologies in the field for the processing of MSW. The process turns MSW into biomass with a consistency that can be considered for use in value-added materials in the construction industry. The problem of MSW management, processing and re-use is common in countries with both advanced and developing economies. While most nations can readily afford the technologies described, any valuation of the proposed methodology must integrate the socio-economic context of the processes to be comprehensive. Ongoing health hazards due to environmental pollution and the social nuisance of the disposal of MSW are a burden to the global economy. Therefore, a radical approach, such as the one proposed in this paper, is needed to minimise the disposal burden of MSW. Successful use of biomass as a construction material will turn MSW into a commodity that is available everywhere in the world.

Similar to any other new technology, there will be numerous challenges ahead mostly associated with adopting the use of biomass as "raw" ingredient for construction products. For instance, seasonal changes in the type of produce will cause variability in the composition of biomass. Other issues 
will include variability in terms of socio-geographic and cultural contexts. All of these can be dealt with in due course, but certainly further research and development work will be necessary.

\section{Conclusions}

The accumulation of MSW is an obvious worldwide environmental concern. It is demonstrated in this paper that the recycling of MSW in the form of an environmentally friendly construction material is a feasible solution. With technological advances and the MSW treatment methods described in this paper, it is possible to process MSW with a level of consistency such that it can subsequently be used as a raw material in a value-added construction material. The cost of natural resource conservation and pollution treatment far outweigh the two-step treatment prescribed herein. Recent publications from various countries around the world reporting on MSW composition, treatment and environmental concerns are summarised in this paper. The waste composition varies and depend on the socio-cultural setting. It is found that generally more than $1 / 3$ of MSW is organic-type waste (biomass), which is non-recyclable and is either incinerated or disposed of in landfills. Both approaches have environmental concerns. However, a review of literature indicates that agro-wastes and industrial wastes have already been used to enhance mechanical properties and as energy efficient and cost-effective sustainable construction materials. To demonstrate the suitability of the material, a sample of biomass was characterised and subsequently used as a part replacement in cement to assess the hydration kinetics and strength evolution of sample pastes. The results overwhelmingly indicate that, despite the expected reduction in compressive strength results, biomass can be used as a construction material.

Author Contributions: All authors contributed equally to this paper.

Funding: This research was funded by University of Melbourne and the Australian Research Council's Discovery Early Career Researcher Grant (DE170100165, DE 2017 R1) and financial support from the Melbourne Research Scholarship. The MSW sample provided by Bioelektra Pty Ltd. is gratefully acknowledged. The authors acknowledge Colin Rawson from Vortex Industrial Solutions Ltd. for processing the MSW sample through the 2018 VIS36500-AUS advanced vortex-oscillation technology with noise attenuation system (PCT/AU2018/050337).

Acknowledgments: The authors thank Mr Tawab Frahmand, director of Oroborus Pty Ltd (Pty) Ltd, for allowing access to confidential information and intellectual property relating to Australian Provisional Patent Application No. 2019900315.

Conflicts of Interest: The authors declare no conflicts of interest.

\section{References}

1. Mian, M.M.; Zeng, X.; Nasry, A.A.N.B.; Al-Hamadani, S.M. Municipal solid waste management in China: A comparative analysis. J. Mater. Cycles Waste Manag. 2017, 19, 1127-1135. [CrossRef]

2. United Nations, Department of Economic and Social Affairs, Population Division. World Population Prospects: The 2015 Revision, Key Findings and Advance Tables; Working Paper No. ESA/P/WP.241; UN: New York, NY, USA, 2015; Available online: https://esa.un.org/unpd/wpp/publications/files/key_findings_ wpp_2015.pdf (accessed on 1 May 2019).

3. Department of the Environment and Energy (DEE). Review of the Application of Landfill Standards. DEE, ACT, Australia. 2010. Available online: http://www.environment.gov.au/protection/nationalwaste-policy/ publications/review-application-landfill-standards. (accessed on 5 June 2018).

4. Ryu, C.; Shin, D. Combined heat and power from municipal solid waste: Current status and issues in South Korea. Energies 2013, 6, 45-57. [CrossRef]

5. Zhang, D.; Huang, G.; Xu, Y.; Gong, Q. Waste-to-energy in China: Key challenges and opportunities. Energies 2015, 8, 14182-14196. [CrossRef]

6. Sverige, A. Energy from Waste-An International Perspective; Rapport U2009; Swedish Waste Management Association: Stockholm, Sweden, 2009; Available online: https://www.avfallsverige.se/aktuellt/nyhetsarkiv/ artikel/energy-from-waste-an-international-perspective/ (accessed on 1 May 2019).

7. Psomopoulos, C.; Bourka, A.; Themelis, N.J. Waste-to-energy: A review of the status and benefits in USA. Waste Manag. 2009, 29, 1718-1724. [CrossRef] [PubMed] 
8. Damgaard, A.; Riber, C.; Fruergaard, T.; Hulgaard, T.; Christensen, T.H. Life-cycle-assessment of the historical development of air pollution control and energy recovery in waste incineration. Waste Manag. 2010, 30, 1244-1250. [CrossRef] [PubMed]

9. Lijó, L.; González-García, S.; Lovarelli, D.; Moreira, M.T.; Feijoo, G.; Bacenetti, J. Life Cycle Assessment of Renewable Energy Production from Biomass. In Life Cycle Assessment of Energy Systems and Sustainable Energy Technologies; Springer: Cham, Switzerland, 2019; pp. 81-98.

10. Hanifzadeh, M.; Nabati, Z.; Longka, P.; Malakul, P.; Apul, D.; Kim, D.S. Life cycle assessment of superheated steam drying technology as a novel cow manure management method. J. Environ. Manag. 2017, 199, 83-90. [CrossRef] [PubMed]

11. Kaufman, S.; Kwon, E.; Krishnan, N.; Castaldi, M.; Themelis, N. Use of statistical entropy and life cycle analysis to evaluate global warming potential of waste management systems. In Proceedings of the 16th Annual North American Waste-to-Energy Conference, Philadelphia, PA, USA, 19-21 May 2008.

12. Balaguer-Dátiz, G.; Krishnan, N. Life cycle comparison of two options for MSW management in Puerto Rico: Thermal treatment vs. modern landfilling. In Proceedings of the 16th Annual North American Waste-to-Energy Conference, Philadelphia, PA, USA, 19-21 May 2008.

13. Psaltis, P.; Komilis, D. Environmental and economic assessment of the use of biodrying before thermal treatment of municipal solid waste. Waste Manag. 2019, 83, 95-103. [CrossRef]

14. Lisk, D.J. Environmental implications of incineration of municipal solid waste and ash disposal. Sci. Total Environ. 1988, 74, 39-66. [CrossRef]

15. Theis, T.L.; Gardner, K.H. Environmental assessment of ash disposal. Crit. Rev. Environ. Sci. Technol. 1990, 20, 21-42. [CrossRef]

16. Vongdala, N.; Tran, H.D.; Xuan, T.; Teschke, R.; Khanh, T. Heavy metal accumulation in water, soil, and plants of municipal solid waste landfill in Vientiane, Laos. Int. J. Environ. Res. Public Health 2019, 16, 22. [CrossRef]

17. Siddique, R. Utilization of coal combustion by-products in sustainable construction materials. Resour. Conserv. Recycl. 2010, 54, 1060-1066. [CrossRef]

18. Carlson, C.L.; Adriano, D.C. Environmental impacts of coal combustion residues. J. Environ. Qual. 1993, $22,227-247$. [CrossRef]

19. Schübeler, P.; Christen, J.; Wehrle, K. Conceptual Framework for Municipal Solid Waste Management in Low-Income Countries; Swiss Center for Development Cooperation: St. Gallen, Switzerland, 1996; Volume 9.

20. Hossain, M.U.; Wu, Z.; Poon, C.S. Comparative environmental evaluation of construction waste management through different waste sorting systems in Hong Kong. Waste Manag. 2017, 69, 325-335. [CrossRef] [PubMed]

21. Jurič, B.; Hanžič, L.; Ilić, R.; Samec, N. Utilization of municipal solid waste bottom ash and recycled aggregate in concrete. Waste Manag. 2006, 26, 1436-1442. [CrossRef]

22. Aubert, J.E.; Husson, B.; Vaquier, A. Use of municipal solid waste incineration fly ash in concrete. Cem. Concr. Res. 2004, 34, 957-963. [CrossRef]

23. Müller, U.; Rübner, K. The microstructure of concrete made with municipal waste incinerator bottom ash as an aggregate component. Cem. Concr. Res. 2006, 36, 1434-1443. [CrossRef]

24. Pickin, J.; Randell, P. Australian National Waste Report 2016; Department of the Environment and Energy: Canberra, Australia, 2017. Available online: https://www.environment.gov.au/system/files/resources/ d075c9bc-45b3-4ac0-a8f2-6494c7d1fa0d/files/national-waste-report-2016.pdf (accessed on 1 May 2019).

25. Wei, Z.; Wang, S.; Xu, J.; Zhou, Y. The technology of the municipal solid wastes composting. Nat. Sci. 2003, 1, 91-94.

26. Peter, A.E.; Nagendra, S.S.; Nambi, I.M. Environmental burden by an open dumpsite in urban India. Waste Manag. 2019, 85, 151-163. [CrossRef]

27. Karak, T.; Bhagat, R.M.; Bhattacharyya, P. Municipal solid waste generation, composition, and management: The world scenario. Crit. Rev. Environ. Sci. Technol. 2012, 42, 1509-1630. [CrossRef]

28. El Sheltawy, S.T.; Fouad, M.M.K.; El Sherbiny, S.A.; Sibak, H.A. Energy Content of Egyptian MSW as a Supporting Tool for Waste-to-Energy (WTE) Approach. In Waste Management and Resource Efficiency; Springer: Singapore, 2019; pp. 707-717.

29. Hogg, D.; Favoino, E.; Nielsen, N.; Thompson, J.; Wood, K.; Penschke, A.; Economides, D.; Papageorgiou, S. Economic Analysis of Options for Managing Biodegradable Municipal Waste-Final Report; EC Report; Eunomia Research and Consulting: Bristol, UK, 2002; Available online: http://ec.europa.eu/environment/ waste/compost/pdf/econanalysis_finalreport.pdf (accessed on 1 May 2019). 
30. Sorokodum, E. Vortex Oscillation Technology. 2018. Available online: http://viesh.ru/old/vortex/v30.htm (accessed on 9 April 2019).

31. Ferronato, N.; Rada, E.C.; Portillo, M.A.G.; Cioca, L.I.; Ragazzi, M.; Torretta, V. Introduction of the circular economy within developing regions: A comparative analysis of advantages and opportunities for waste valorization. J. Environ. Manag. 2019, 230, 366-378. [CrossRef]

32. Pocketbook, F.S. World Food and Agriculture 2015; FAO: Rome, Italy, 2015.

33. Onyelowe, K.C. Nanosized palm bunch ash (NPBA) stabilisation of lateritic soil for construction purposes. Int. J. Geotech. Eng. 2019, 13, 83-91. [CrossRef]

34. Mohamad, N.; Samad, A.A.A.; Lakhiar, M.T.; Mydin, M.A.O.; Jusoh, S.; Sofia, A.; Efendi, S.A. Effects of Incorporating Banana Skin Powder (BSP) and Palm Oil Fuel Ash (POFA) on mechanical properties of lightweight foamed concrete. Int. J. Integr. Eng. 2019, 10. [CrossRef]

35. Aprianti, E.; Shafigh, P.; Bahri, S.; Farahani, J.N. Supplementary cementitious materials origin from agricultural wastes-A review. Constr. Build. Mater. 2015, 74, 176-187. [CrossRef]

36. Pode, R. Potential applications of rice husk ash waste from rice husk biomass power plant. Renew. Sustain. Energy Rev. 2016, 53, 1468-1485. [CrossRef]

37. Jauberthie, R.; Rendell, F.; Tamba, S.; Cissé, I.K. Properties of cement-Rice husk mixture. Constr. Build. Mater. 2003, 17, 239-243. [CrossRef]

38. Ganiron, T.U., Jr.; Ucol-Ganiron, N.; Ganiron, T.U., III. Recycling of waste coconut shells as substitute for aggregates in mix proportioning of concrete hollow blocks. World Sci. News 2017, 77, 107-123.

39. Akhtar, N.; Patel, S. Agro-Industrial Discards and Invasive Weed-Based Lignocelluloses as Green Building Materials: A Pertinent Review. In Ecological Wisdom Inspired Restoration Engineering; Springer: Singapore, 2019; pp. 121-130.

40. Madurwar, M.V.; Ralegaonkar, R.V.; Mandavgane, S.A. Application of agro-waste for sustainable construction materials: A review. Constr. Build. Mater. 2013, 38, 872-878. [CrossRef]

41. Yang, H.S.; Kim, D.J.; Kim, H.J. Rice straw-Wood particle composite for sound absorbing wooden construction materials. Bioresour. Technol. 2003, 86, 117-121. [CrossRef]

42. Mohajerani, A.; Ukwatta, A.; Jeffrey-Bailey, T.; Swaney, M.; Ahmed, M.; Rodwell, G.; Bartolo, S.; Eshtiaghi, N.; Setunge, S. A Proposal for Recycling the World's Unused Stockpiles of Treated Wastewater Sludge (Biosolids) in Fired-Clay Bricks. Buildings 2019, 9, 14. [CrossRef]

43. Kua, T.A.; Arulrajah, A.; Horpibulsuk, S.; Du, Y.J.; Shen, S.L. Strength assessment of spent coffee grounds-geopolymer cement utilizing slag and fly ash precursors. Constr. Build. Mater. 2016, 115, 565-575. [CrossRef]

44. Khedari, J.; Suttisonk, B.; Pratinthong, N.; Hirunlabh, J. New lightweight composite construction materials with low thermal conductivity. Cem. Concr. Compos. 2001, 23, 65-70. [CrossRef]

45. Torkaman, J.; Ashori, A.; Momtazi, A.S. Using wood fiber waste, rice husk ash, and limestone powder waste as cement replacement materials for lightweight concrete blocks. Constr. Build. Mater. 2014, 50, 432-436. [CrossRef]

46. Wolfe, R.W.; Gjinolli, A. Durability and strength of cement-bonded wood particle composites made from construction waste. For. Prod. J. 1999, 49, 24-31.

47. Modolo, R.; Ferreira, V.M.; Machado, L.M.; Rodrigues, M.; Coelho, I. Construction materials as a waste management solution for cellulose sludge. Waste Manag. 2011, 31, 370-377. [CrossRef] [PubMed]

48. Basta, A.H.; Safain, M.Z.; El-Rewainy, I. Role of some treatments on enhancing the eco-friendly utilization of lignocellulosic wastes in production of cement-fiber bricks. BioResources 2011, 6, 1359-1375.

49. Tolêdo Filho, R.D.; Joseph, K.; Ghavami, K.; England, G.L. The use of sisal fibre as reinforcement in cement based composites. Rev. Bras. Eng. Agríc. Ambient. 1999, 3, 245-256. [CrossRef]

50. Aymerich, F.; Fenu, L.; Meloni, P. Effect of reinforcing wool fibres on fracture and energy absorption properties of an earthen material. Constr. Build. Mater. 2012, 27, 66-72. [CrossRef]

51. Awal, A.; Mohammadhosseini, H.; Hossain, M.Z. Strength, modulus of elasticity and shrinkage behaviour of concrete containing waste carpet fiber. Int. J. Geomate 2015, 9, 1441-1446.

52. Ganiron, J.T. Effects of human hair additives in compressive strength of asphalt cement mixture. Int. J. Adv. Sci. Technol. 2014, 67, 11-22. [CrossRef]

53. Butt, W.A.; Mir, B.; Jha, J. Strength behavior of clayey soil reinforced with human hair as a natural fibre. Geotech. Geol. Eng. 2016, 34, 411-417. [CrossRef] 
54. Arnaud, L.; Gourlay, E. Experimental study of parameters influencing mechanical properties of hemp concretes. Constr. Build. Mater. 2012, 28, 50-56. [CrossRef]

55. Benfratello, S.; Capitano, C.; Peri, G.; Rizzo, G.; Scaccianoce, G.; Sorrentino, G. Thermal and structural properties of a hemp-lime biocomposite. Constr. Build. Mater. 2013, 48, 745-754. [CrossRef]

56. Bentchikou, M.; Guidoum, A.; Scrivener, K.; Silhadi, K.; Hanini, S. Effect of recycled cellulose fibres on the properties of lightweight cement composite matrix. Constr. Build. Mater. 2012, 34, 451-456. [CrossRef]

57. Coutts, R.S. A review of Australian research into natural fibre cement composites. Cem. Concr. Compos. 2005, 27, 518-526. [CrossRef]

58. Chestnut, R.; Colussi, J.J.; Frost, D.J.; Keen, W.E., Jr.; Raduta, M.C. Method of Stabilizing Organic Waste. U.S. Patent 4,514,307, 30 April 1985. Available online: https://patentimages.storage.googleapis.com/25/24/03/ 23acbbfbe088d0/US4514307.pdf (accessed on 7 May 2019).

59. Dittenber, D.B.; GangaRao, H.V. Critical review of recent publications on use of natural composites in infrastructure. Compos. Part A Appl. Sci. Manuf. 2012, 43, 1419-1429. [CrossRef]

60. Zeiss, C.; Atwater, J. Waste disposal facilities and community response: Tracing pathways from facility impacts to community attitude. Can. J. Civ. Eng. 1991, 18, 83-96. [CrossRef]

61. Ding, Y.; Xiong, J.; Zhou, B.; Wei, J.; Qian, A.; Zhang, H.; Zhu, W.; Zhu, J. Odor removal by and microbial community in the enhanced landfill cover materials containing biochar-added sludge compost under different operating parameters. Waste Manag. 2019, 87, 679-690. [CrossRef]

62. Kawasaki, H.; Horiuchi, S.; Akatsuka, M.; Sano, S. Fly-ash slurry island: II. Construction in Hakucho Ohashi project. J. Mater. Civ. Eng. 1992, 4, 134-152. [CrossRef]

63. John, V.; Zordan, S. Research \& development methodology for recycling residues as building materials-A proposal. Waste Manag. 2001, 21, 213-219. [PubMed]

64. Jessica Clifford, New recycling technology to keep 90 per cent of household waste out of landfill, ABC Illawarra. Available online: https://www.abc.net.au/news/2019-01-23/new-recycle-technology-to-keep-90pcof-waste-out-of-landfill/10736142 (accessed on 2 May 2019).

65. Louis, G.E. A historical context of municipal solid waste management in the United States. Waste Manag. Res. 2004, 22, 306-322. [CrossRef]

66. Mallock, W. Ch 2 Background to Sterlisation-An Historical Introduction in Healthcare Sterilisation: Introduction and Standard Practices, Volume 1, Wayne, J. Rogers; Smithers Rapra Technology Ltd: Shawbury, UK, 2013; Available online: http://www.smithersrapra.com/SmithersRapra/media/Sample-Chapters/HealthcareSterilisation-Volume-1.pdf (accessed on 2 May 2019).

67. Sanderson, R.S. Sterilizing and Storing Medical Items. U.S. Patent 4,105,407, 8 August 1978.

68. Barnes, J.D.; Meador, D.; Brock, D.A.; Janus, P.; Seebach, C.F.N.; ICE, C.L.; Youds, M.; Jarrett, C. Apparatus for Processing a Material and Fan Therefor. IPN WO 89/35756, 1998.

69. Platzer, M.F.; Sorokodum, E. On propulsion due to wavy flow. Int. J. Des. Nat. Ecodyn. 2008, 3, 109-120.

70. Petersen, D.E.; Donald, E. Media Granulation Apparatus. U.S. Patent 5,402,947, 4 April 1995. Available online: https://patentimages.storage.googleapis.com/35/be/45/9d15a25d5969f1/US5402947.pdf (accessed on 7 May 2019).

71. Rawson, C. Aero-Acoustic Materials Processing Plant with Noise Attenuation System. Patent No WO2018187848A1, 18 October 2018. Available online: https://patentimages.storage.googleapis.com/1d/aa/d1/ 5c8c11bad3c9f7/WO2018187848A1.pdf (accessed on 7 May 2019).

(C) 2019 by the authors. Licensee MDPI, Basel, Switzerland. This article is an open access article distributed under the terms and conditions of the Creative Commons Attribution (CC BY) license (http://creativecommons.org/licenses/by/4.0/). 